\title{
Gross Features of Human Placentae in Normal and Gestational Diabetes Mellitus
}

\author{
Molly A. J. ${ }^{1}$, Usha Devi K.B. ${ }^{2}$ \\ ${ }^{1}$ Department of Health Services, Primary Health Centre Keezhpally, Kannur, Kerala, India. \\ ${ }^{2}$ Department of Anatomy, Govt. T.D. Medical College, Alappuzha, Kerala, India.
}

\section{ABSTRACT}

\section{BACKGROUND}

Placenta is a multifunctional fetomaternal organ that plays an important role during pregnancy. Gestational diabetes mellitus (GDM) is reflected on placenta both macroscopically and microscopically as enlargement of placenta, abnormalities in villi and degenerative changes.

\section{METHODS}

This is a cross sectional study conducted among two groups, normal group and GDM group, to compare the gross features of GDM placentae in the Department of Obstetrics and Gynaecology and Department of Anatomy, Govt. Medical College, Thiruvananthapuram.

\section{RESULTS}

The study was conducted on 65 normal and 65 GDM placentae. There was an increased incidence of gestational diabetes mellitus in the age group $>25$ years with a mean age of $26.38 \pm 3.84$ years. Multiparous women have been found to be more prone to gestational diabetes mellitus. Past history of abortions and intrauterine death (IUD) was more in GDM group as compared to normal group. Incidence of lower segment caesarean section (LSCS) was also more in GDM group. Weight, diameter and number of maternal cotyledons of placentae were significantly increased in GDM. The predominant shape of placenta in both groups was round, next to that was oval. Only 3 placentae showed irregular shape and that was from GDM group. Most common type of attachment of umbilical cord was eccentric in both groups. Next to that was central and marginal respectively. Only one placenta was furcate and that belonged to GDM group. Fetal membrane was translucent in all normal and GDM placentae. Mean birth weight of the baby of GDM mothers was significantly increased. Mean fetoplacental weight ratio was significantly decreased in GDM group as compared to normal group.

\section{CONCLUSIONS}

In the present study, GDM placentae showed significant changes in gross features. Meticulous gross examination of a placenta prior to histologic sectioning enhances microscopic interpretation. By increasing our understanding of the placenta, it may be possible to prevent and treat placental abnormalities related to GDM, thus ensuring lifelong health of the child and the mother. Hence, the present work would provide vital information to both obstetricians and neonatologists.

\section{KEY WORDS}

Placenta, Gestational Diabetes Mellitus, Morphology of Placenta
Corresponding Author: Dr. Usha Devi KB., Krishna, Kulangarakonam, Neruvamoodu (P.O), Nemom, Thiruvananthapuram, Kerala, India.

E-mail: ushakbdevi1@gmail.com

DOI: $10.14260 /$ jemds/2021/216

How to Cite This Article: Molly AJ, Devi UKB. Gross features of human placentae in normal and gestational diabetes mellitus. J Evolution Med Dent Sci 2021;10(14):1008-1013, $10.14260 /$ jemds/2021/216 DOI:

Submission 26-09-2020,

Peer Review 04-12-2020,

Acceptance 10-12-2020,

Published 05-04-2021.

Copyright (C) 2021 Molly A. J. et al. This is an open access article distributed under Creative Commons Attribution License [Attribution 4.0 International (CC BY 4.0)] 


\section{BACKGROUND}

Placenta is a fetomaternal organ which connects the developing fetus to the uterine wall of the mother. It is responsible for the exchange of gaseous and metabolic products between fetal and maternal circulations and synthesis of hormone. It is essential for maintenance of pregnancy and for promoting normal growth and development of fetus. It begins to meet the demand of the embryo as early as third week of intrauterine life. The placenta was recognised for the first time as an endocrine organ in the beginning of $20^{\text {th }}$ century and the new focus became on the transfer of solutes across the placenta. Despite this journey of evolving understanding of the complexities of the placenta, significant knowledge gaps remain in understanding placental functions. The human placental project sponsored by National Institute of Health (NIH) described eloquently the need for continuing research in this field. The placenta is the least understood human organ and perhaps one of the most important organ for the health of a woman and her fetus during pregnancy, also for the lifelong health of both. ${ }^{1}$

'Placenta' is a Latin word, the Greek equivalent word plakuos means a flat cake. ${ }^{2}$ The term placenta was coined by an Italian surgeon and anatomist, Realdo Colombo. It is a discoid mass, having maternal and fetal surfaces and a peripheral margin. Maternal surface is finely granular and fetal surface is smooth, covered by amnion with the umbilical cord attached to it. The placenta continuously undergoes changes in shape, weight, structure and functions throughout gestation. It is considered as a window through which maternal dysfunction and their impacts on fetal well-being can be understood. Pregnancy is a diabetogenic state by virtue of various physiological changes which cause insulin resistance. In normal pregnancy, glucose tolerance decreases by third trimester, though plasma levels of insulin increase. Gestational diabetes mellitus (GDM) is described as glucose intolerance of varying severity with the onset of first recognition during pregnancy and disappears with delivery. ${ }^{3}$ About $2-5 \%$ of the total pregnancies may be affected by diabetes mellitus. Among pregnancies complicated by diabetes mellitus, about $65 \%$ cases involve gestational diabetes mellitus. ${ }^{4}$ India has been called 'the diabetic capital of the world'. In India the prevalence of GDM is $4-11.6 \%$ in urban population and $3 \%$ in rural population, varies according to geographical areas and diagnostic methods employed. 5

The placenta of diabetic women has attracted much interest because diabetic pregnancy is characterised by numerous disturbances in fetal growth and development. ${ }^{6}$ GDM in pregnancy is reflected on placenta both macroscopically and microscopically such as enlargement of placenta, abnormalities in villi and degenerative changes. This results in reduced blood flow and utero-placental insufficiency which may lead to fetal hypoxia, congenital fetal malformations and unexplained intrauterine death. The extent of these changes depends on a number of factors particularly the quality of glycemic control achieved during the critical periods in placental development. ${ }^{7}$

The examination of placenta is of critical value as it can be used in gathering knowledge about identification of pathological process contributing to the adverse outcome and management conducted during pregnancy. This study was conducted to increase our understanding of the placenta, to prevent and treat placental abnormalities related to GDM, to ensure lifelong health of the child and the mother. Hence, the present work would provide vital information to both obstetricians and neonatologists.

\section{METHODS}

A cross sectional study with a comparison group was carried out between $09 / 02 / 2017$ to $08 / 08 / 2018$ to explore the gross features of placentae from normal pregnancies and pregnancies complicated with GDM. The study was conducted after approval by the human ethics committee, Govt. Medical College, and Thiruvananthapuram.

After obtaining informed consent from the mothers, gross features of placenta were studied.

\section{Sample Size}

Sample size for the current study was calculated using the information provided by Alpana Hatibaruah in the article "A study on macroscopic anatomy of human placenta". In this study $62.16 \%$ of normal placentae at term were found to weigh between 400 - 499 grams.

Sample Size,

$\mathrm{N}=4 \mathrm{PQ} / \mathrm{d}^{2}$

$\mathrm{P}=62(62.16)$

$\mathrm{Q}=100-62=38$

d, precision $=20 \%$ of $\mathrm{P}=12.4$

$\mathrm{N}=4 \times 62 \times 38 /(12.4 \times 12.4)^{2}$

$=61.29$

Sample size was taken as 65 .

Equal number of placentae from pregnancies complicated with GDM were taken and compared with that of normal pregnancies. Purposive type of non-probability sampling method was used.

\section{Inclusion Criteria}

- Placentae from normal pregnancies with gestational age $>24$ weeks.

- Placentae from GDM complicated pregnancies with gestational age $>24$ weeks.

\section{Exclusion Criteria}

- Multiple pregnancies, pregnancies with pre-existing diabetes mellitus.

- Pregnancies complicated with pregnancy induced hypertension, hypothyroidism, anaemia, abruptio placenta, jaundice and malnutrition.

\section{Study Variables}

- Weight of Placenta.

- Diameter of placenta. 
- Shape of placenta.

- Colour of the membrane.

- Number of maternal cotyledons.

- Type of attachment of umbilical cord.

- Fetoplacental weight ratio.

\section{Placental Weight}

Placental weight was measured by directly placing the placenta on standardised weighing machine and expressed in grams.

\section{Placental Diameter}

The placenta was placed on a flat surface. At first, the maximum diameter was measured with a non-stretchable measuring tape graduated in centimetres. Then, second maximum diameter was recorded at right angles to the first one. The mean of two diameters was considered as the diameter of the placenta, expressed in centimetres.

\section{Shape of the Placenta}

Each placenta was categorised as round, oval or irregular in shape. Type of attachment of umbilical cord and colour of the fetal membrane were observed and recorded.

\section{Number of Maternal Cotyledons}

Gentle pressure was applied on centre of the fetal surface of placenta. As a result the cotyledons on the maternal surface became prominent. The placenta was then placed on a flat surface with maternal side facing upwards and total number of cotyledons were recorded.

\section{Fetoplacental Weight Ratio}

It is the ratio of fetal weight (taken from the case sheet of the mother) and the placental weight.

Maternal and fetal parameters such as gestational age, parity, mode of delivery and birth weight of the baby were recorded from the case sheet.

\section{Statistical Analysis}

Data was entered in Microsoft Excel sheet and statistical analysis was performed using Statistical Package for the Social Sciences (SPSS) version 16. Quantitative variables were described by mean and standard deviation. Statistical test of significance for quantitative variables was Student's t-test. Categorical variables were analysed by proportion. Statistical test of significance for categorical variables was chi-square test. A 'P-value' less than 0.05 was considered to be statistically significant.

\section{RESULTS}

\section{Maternal Age}

Mean age of GDM mothers $(26.38 \pm 3.84)$ was more than that of normal mothers $(24.34 \pm 4.29)$ and it was statistically significant. As compared to normal mothers, percentage of GDM mothers were more in advanced age group.

\begin{tabular}{|c|c|c|c|c|c|c|c|c|c|}
\hline \multirow{2}{*}{ Age in Years } & \multicolumn{2}{|c|}{ Normal } & \multicolumn{2}{|c|}{ GDM } & \multicolumn{2}{|c|}{ Total } & \multirow{2}{*}{$\chi^{2}$} & \multirow{2}{*}{ Df } & \multirow{2}{*}{$\mathbf{P}$} \\
\hline & $\mathbf{N}$ & $\%$ & $\mathbf{N}$ & $\%$ & $\mathbf{N}$ & $\%$ & & & \\
\hline $20-25$ & 41 & 63.1 & 30 & 46.2 & 71 & 54.6 & & & \\
\hline $26-30$ & 19 & 29.2 & 24 & 36.9 & 43 & 33.1 & & & \\
\hline$>30$ & 5 & 7.7 & 11 & 16.9 & 16 & 12.3 & & & \\
\hline Total & 65 & 100 & 65 & 100 & 130 & 100 & 4.536 & 2 & .104 \\
\hline
\end{tabular}

\section{Gestational Age}

Mean gestational age at delivery in GDM was $38.25 \pm 1.11$ and in normal pregnancies, it was $38.32 \pm 1.53$. Maximum gestational age in normal group was 40.43 and in GDM group it was 40.14. Minimum gestational age in GDM group was 35.43 , but in normal group, it was 34.43 . There was not much difference in mean gestational age between normal and GDM pregnancies and it was statistically insignificant.

\begin{tabular}{|c|c|c|c|c|}
\hline & \multicolumn{2}{|c|}{ Gestational Age } & \multirow{2}{*}{$\mathbf{t}$} & \multirow{2}{*}{$\mathbf{P}$} \\
\hline & Mean & SD & & \\
\hline Normal & 38.32 & 1.53 & 0.318 & 0.751 \\
\hline GDM & 38.25 & 1.11 & & \\
\hline \multicolumn{5}{|c|}{ Table 2. Mean Gestational Age } \\
\hline
\end{tabular}

\section{Gravida}

It represents the total number of pregnancies including present pregnancy. Primi gravidae were more in the normal group, whereas multi gravidae were more in GDM group.

\begin{tabular}{|c|c|c|c|c|c|c|c|c|c|}
\hline \multirow{2}{*}{ Gravida } & \multicolumn{2}{|c|}{ Normal } & \multicolumn{2}{|c|}{ GDM } & \multicolumn{2}{|c|}{ Total } & \multirow{2}{*}{$\chi^{2}$} & \multirow{2}{*}{ Df } & \multirow{2}{*}{$\mathbf{P}$} \\
\hline & $\mathbf{N}$ & $\%$ & $\mathbf{N}$ & $\%$ & $\mathbf{N}$ & $\%$ & & & \\
\hline $\mathrm{G}_{1}$ & 43 & 66.2 & 30 & 46.2 & 73 & 56.2 & & & \\
\hline $\mathrm{G}_{2}$ & 19 & 29.2 & 22 & 33.8 & 41 & 31.5 & & & \\
\hline $\mathrm{G}_{3}$ & 1 & 1.5 & 9 & 13.8 & 10 & 7.7 & & & \\
\hline $\mathrm{G}_{4}$ & 2 & 3.1 & 2 & 3.1 & 4 & 3.1 & & & \\
\hline $\mathrm{G}_{5}$ & 0 & & 1 & 1.5 & 1 & 0.8 & & & \\
\hline $\mathrm{G}_{6}$ & 0 & & 1 & 1.5 & 1 & 0.8 & & & \\
\hline Total & 65 & 100 & 65 & 100 & 130 & 100 & 10.935 & 5 & 0.053 \\
\hline
\end{tabular}

\section{DISCUSSION}

Placenta is a fascinating multifunctional organ that plays an important role during pregnancy by being intimately connected to the mother and the baby. The importance of placenta cannot be ignored. Being an exceptional and easily accessible source of information, it gives an idea about the intrauterine environment. Placental examination can shed light upon factors pertaining to the current pregnancy and its outcome, guide postpartum management, provide insight into clinical problems that become evident hours or days after delivery and predictive of future pregnancies.

The placenta can provide exceedingly useful information relating to perinatal morbidity and mortality. In order to derive clinically useful information from the placenta, macroscopic examination is the first step. Meticulous gross examination of a placenta prior to histologic sectioning enhances microscopic interpretation. The placental histology can add useful information in ascertaining the cause and mechanism involved in adverse pregnancy outcomes. Gestational diabetes mellitus (GDM) in pregnancy is reflected on placenta both macroscopically and microscopically. ${ }^{8}$ 


\section{Maternal Age}

In the present study, majority of normal mothers were found in the age group 20 - 25 years and GDM mothers were seen in more than 25 years of age. Emmanuel Odar (2004) observed that the age group at risk of getting gestational diabetes was between 20 - 39 years in $96.8 \%$ of cases. ${ }^{9}$ Henaan Jeelani (2014) has documented mean age of GDM mothers (29.2 \pm 3.5 ) was more than that of normal mothers $(28.9 \pm 4.3)$. According to him in control group, age was ranging from 23 - 35 years, whereas in GDM, it was ranging from $24-36$ years. ${ }^{10}$ Vaishali M Paunikar (2015) reported that $70 \%$ of GDM mothers belonged to more than 25 years of age. This correlated well with our study where we have observed that mean age of diabetic mothers $(26.38 \pm 3.84)$ was significantly more as compared to normal mothers $(24.34 \pm 4.29)$. Mishra P et al. (2017) has documented that majority $(82.5 \%)$ of diabetic mothers were above 30 years of age. Nidhi Mishra et al. (2017) also opined that in diabetic group, majority of the cases (85\%) were between the age of 20 - 30 years. ${ }^{11}$ The optimal age of women for pregnancy and delivery is between 20 and 29 years, pregnancies of women older than 35 years are considered at risk. ${ }^{12}$ The age of the mother has an influence on the placental function during pregnancy and delivery. ${ }^{13}$ It has been well documented that the risks for premature delivery and fetal complications are higher in pregnancies of older women of more than 25 years of age. ${ }^{14}$

\section{Gestational Age}

Taricco et al. (2009) reported that mean gestational age in control was $38.5 \pm 0.6$ and in GDM it was $38.2 \pm 0.6 .15$ Ana Karina Marques Salge et al. (2012) found that mean gestational age of the diabetic women was 38.51 weeks. ${ }^{16}$ According to the study done by Henaan Jeelani (2014), mean gestational age in control group was $38.3 \pm 1.1$ and in GDM, it was $37.3 \pm 0.5$. Here gestational age was significantly more in GDM. ${ }^{10}$ In our study, gestational age in GDM group was less than control group. The mean gestational age in normal group was $38.32 \pm 1.53$, while in GDM, it was found to be $38.25 \pm 1.11$. Hence, the gestational age in GDM group was less as compared to normal group which was statistically insignificant (P-value is 0.751). GDM pregnancies (especially GDM on insulin) were terminated earlier (around 38 weeks) to prevent maternal and fetal complications due to large size of the baby.

\section{Parity}

In our study, percentage of multiparous women was more in GDM group as compared to normal. This finding was in harmony with Henaan Jeelani (2014) who observed that 51.5 $\%$ of normal mothers and $48.5 \%$ of GDM mothers were primigravidae, whereas $40.8 \%$ of normal and $59.2 \%$ of GDM mothers were multigravidae ${ }^{10}$ and Vaishali M Paunikar (2015) reported that percentage of multiparous women was more in GDM group (22 out of 30 cases). Nidhi Mishra et al. (2017) documented that $52.5 \%$ of normal group were primi as compared to $35 \%$ cases of diabetic group, while only $47.5 \%$ in normal group were multi gavidae as compared to $65 \%$ cases in diabetic group. ${ }^{11}$ Mishra $\mathrm{P}$ et al. (2017) reported that among diabetic mothers, maximum cases were multipara, 27 $(67.5 \%)$ as compared to normal pregnant mothers, 06 (15\%).

\section{Obstetric Risks in the Past}

Our study revealed that abortion accounts for $24.6 \%$ in GDM group as compared to $10.8 \%$ in normal and past history of IUD was more in GDM group ( $4.6 \%$ vs. $1.5 \%$ ). Our findings were in concordance with Ahia Garshasbi et al. (2008) who reported that past history of abortion and still birth were more in GDM mothers as compared to non-diabetic group. ${ }^{17}$ Abdulbari Bener et al. (2011) observed that past obstetric risk of abortion and still birth were more in GDM group as compared to normal ( $24 \%$ and $11.8 \%$ vs. $16.9 \%$ and $7.9 \%$ ). ${ }^{18}$

\section{Mode of Delivery}

In the present study, 21 (32.3\%) GDM mothers underwent LSCS as compared to 8 (12.3\%) normal mothers. In the study conducted by Abdulbari Bener et al. (2011), incidence of LSCS was significantly higher in GDM women $(27.9 \%$ vs. $12.4 \%$; $P$ <0.001). ${ }^{18}$ According to Tulika Goswami Mahanta et al. a total of $22 \%$ LSCS was performed in non-GDM group whereas the percentage of LSCS in GDM group was high, accounting for 60.7 $\% .{ }^{19}$ In our study, incidence of LSCS was more in GDM pregnancies. This finding was similar with the previous studies. Increased incidence of LSCS may be due to large size of the baby in GDM and previous history of LSCS.

\section{Weight of the Placenta}

\begin{tabular}{|ccc|}
\hline Authors & $\begin{array}{c}\text { Control } \\
\text { (Mean } \pm \text { SD) }\end{array}$ & $\begin{array}{c}\text { GDM } \\
\text { (Mean } \pm \text { SD) }\end{array}$ \\
Soma Saha et al. $(2013)^{20}$ & $504.42 \pm 48.11$ & $565.75 \pm 41.04$ \\
Sadaf Parvez Hussain et al. (2013) & $527.20 \pm 15.69$ & $582.56 \pm 28.61$ \\
Lal Bakshkhaskhelli et al. (2013) $^{21}$ & $499.0 \pm 21.00$ & $967.5 \pm 32.50$ \\
Henaan Jeelani et al. (2014) ${ }^{10}$ & $511.0 \pm 36.5$ & $89.3 \pm 66.5$ \\
Geena Augustine et al. (2016) 22 & $462.20 \pm 8.57$ & $560.10 \pm 77.91$ \\
Sharmila Bhanu et al. (2017) & $412.08 \pm 54.03$ & $537.27 \pm 131.97$ \\
Mishra P et al. (2017) & $487.88 \pm 25.40$ & $557.90 \pm 56.50$ \\
Nidhi Mishra et al. (2017) ${ }^{11}$ & $469.63 \pm 88.39$ & $563.75 \pm 96.78$ \\
Present study & $492.00 \pm 55.42$ & $629.88 \pm 88.29$ \\
\hline Table 1. Comparison of Mean Placental Weight in Different Studies \\
\hline \multicolumn{2}{|c}{} \\
\hline
\end{tabular}

In the present study, the placental weight was significantly higher in GDM group which was in conformity with the previous studies. The increased placental weight in diabetes may be because of reactionary hyperglycaemia in fetuses of diabetic mothers which leads to compensatory hyperplasia of the villous structure and fetal macrosomia. Another factor which leads to villous hyperplasia could be the vascular compromise in diabetes mellitus which causes low oxygen tension in chorionic villous blood. ${ }^{24}$ In moderate or severe cases of GDM, placentas would be exposed to exacerbated hypoxia, oxidative and nitrative stresses which might highly stimulate trophoblast proliferation ending in a significant increase of placental weight. ${ }^{25}$ According to Teasdale, increased placental weight was due to placental hyperplasia in response to diabetes and appeared in the form of a moderate increase in parenchymatous (syncytio-vascular) tissue and the significant accumulation of non-parenchymatous tissue (stroma, glycogen, lipids and tissue fluid oedema). ${ }^{26}$

\section{Shape of Placenta}

In the present study, most common shape encountered in both normal and GDM groups was round. This finding was corresponding with the study done by Nidhi Mishra. In contrast 
to our findings, Ahmed TM Elshennawy found that most of the placentae in both groups were oval in shape. According to Vandana Tiwari, most common shape of GDM placentae was round, but in normal group, it was oval. Round and oval shapes are considered as normal shapes of placenta.

\begin{tabular}{|ccccc|}
\hline Authors & Groups & Round & Oval & Irregular \\
\hline Vandana Tiwari et al. (2015) ${ }^{27}$ & GDM & $52 \%$ & $42 \%$ & $6 \%$ \\
& Normal & $20 \%$ & $70 \%$ & $10 \%$ \\
Ahmed TM Elshennawy et al. (2016) ${ }^{28}$ & GDM & $40 \%$ & $60 \%$ & $0 \%$ \\
& Normal & $45 \%$ & $55 \%$ & $0 \%$ \\
Nidhi Mishra et al. (2017) ${ }^{11}$ & GDM & $50 \%$ & $40 \%$ & $10 \%$ \\
& Normal & $60 \%$ & $40 \%$ & $0 \%$ \\
Present study & GDM & $73.8 \%$ & $21.5 \%$ & $4.6 \%$ \\
& Normal & $75.4 \%$ & $24.6 \%$ & $0 \%$ \\
\hline Table 2. Comparison of Shape of Placentae in Different Studies \\
\hline
\end{tabular}

\section{CONCLUSIONS}

In the present study, GDM placentae showed significant changes in gross features. Meticulous gross examination of a placenta prior to histologic sectioning enhances microscopic interpretation. By increasing our understanding of the placenta, it may be possible to prevent and treat placental abnormalities related to GDM, thus ensuring lifelong health of the child and the mother. Hence, the present work would provide vital information to both obstetricians and neonatologists.

Data sharing statement provided by the authors is available with the full text of this article at jemds.com.

Financial or other competing interests: None.

Disclosure forms provided by the authors are available with the full text of this article at jemds.com.

\section{REFERENCES}

[1] Mir IN, Chalak L. Placenta-the least understood human organ - from animistic origins to human placental project. Annals of Reproductive Medicine and Treatment 2017;2(2):1013.

[2] Hamilton WJ, Mossaman HW. Hamilton, Boyd and Mossman's Human Embryology. In: Alimentary and respiratory system, pleural and peritoneal cavity. $4^{\text {th }}$ edn. London: The Macmillan Press Ltd., 1976: p. 291-376.

[3] Metzger BE, Coustan DR. Summary and recommendations of the Fourth International Workshop-Conference on Gestational Diabetes Mellitus. The Organising Committee. Diabetes Care 1998;21(Suppl 2):B161-7.

[4] Saxena R. Bedside obstetrics and gynaecology. Chap - 13. In: Gestational Diabetes. New Delhi: Jaypee Brothers Medical Publishers Pvt Ltd., 2010: p. 234-55.

[5] Kumar A, Goel MK, Jain RB, et al. India towards diabetes control: key issues. Australas Med J 2013;6(10):524-31.

[6] Coustan DR. Management of high risk pregnancy. In: Gestational Diabetes. Vol. 4. England: Blackwell Science 1999: p. 261-9.

[7] Desoye G, Shafrir E. The human placenta in diabetic pregnancy. Diabetes Reviews 1996;4(1):70-89.

[8] Jaiman S. Gross examination of the placenta and its importance in evaluating an unexplained intrauterine fetal demise. Journal of Fetal Medicine 2015;2:113-20.
[9] Odar E, Wandabwa J, Kiondo P. Maternal and fetal outcome of gestational diabetes mellitus in Mulago Hospital, Uganda. Afr Health Sci 2004;4(1):9-14.

[10] Jeelani H, Jabeen F, Qureshi A, et al. Gross morphological alterations and birth weight in gestational diabetes mellitus: a case control study. JK Practitioner 2015;20(12):17-20.

[11] Mishra N, Jamila A, Devi NS. Pathological changes in placentas of diabetic mothers \& its association with fetal outcome. IOSR Journal of Dental and Medical Sciences (IOSR - JDMS) 2017;16(8):93-9.

[12] Miletic T, Aberle N, Mikulandra F, et al. Prenatal outcome of pregnancies in women aged 40 and over. Coll Antropol 2002;26(1):251-8.

[13] Hansen JP. Older maternal age and pregnancy outcome:a review of the literature. Obestetric Gynecol Surv 1986;41(11):726-42.

[14] Fretts RC, Schmittediel J, McLean FH, et al. Increased maternal age and the risk of fetal death. N Engl J Med 1995;333(15):953-7.

[15] Taricco E, Radaelli T, Rossi G, et al. Effects of gestational diabetes on fetal oxygen and glucose levels in vivo. BJOG 2009;116(13):1729-35.

[16] Salge AKM, Rocha KMN, Xavier RM, et al. Placental changes in diabetes mellitus. Clinics (Sao Paulo) 2012;67(10):1203-8.

[17] Garshasbi A, Faghihzadeh S, Naghizadeh MM, et al. Prevalence and risk factors for gestational diabetes mellitus in Tehran. Journal of Family and Reproductive Health 2008;2(2):75-80.

[18] Bener A, Saleh NM, Al-Hamaq A. Prevalence of gestational diabetes and associated maternal and neonatal complications in a fast-developing community: global comparisons. Int J Womens Health 2011;3:367-73.

[19] Mahanta TG, Deuri A, Mahanta BN, et al. Maternal and foetal outcome of gestational diabetes mellitus in a rural block of Assam, India. Clinical Epidemiology and Global Health 2014;2(1):3-8.

[20] Saha S, Biswas S, Mitra D, et al. Histologic and morphometric study of human placenta in gestational diabetes mellitus. Ital J Anat Embryol 2014;119(1):1-9.

[21] Khaskhelli LB, Memon S, Goswami P, et al. Change in normal morphology of placenta and Its possible effects on fetal outcome in diabetic mothers as compared to nondiabetic mothers. Journal of the Liaquat University of Medical and Health Sciences 2013;12(1):49-54.

[22] Augustine G, Pulikkathodi M, Renjith S, et al. A study of placental histological changes in gestational diabetes mellitus on account of fetal hypoxia. Int J Med Sci Public Health 2016;5(12):2457-60.

[23] Bhanu PS, Sankar D, Kiran S, et al. Gross morphological study of gestational diabetes mellitus placenta from south indian mothers compared with control placenta. International Journal of Anatomy and Research 2017;5(1.2):3521-6.

[24] Calderon IM, Damasceno DC, Amorin RL, et al. Morphometric study of placental villi and vessels in women with mild hyperglycemia or gestational or overt diabetes. Diabetes Res Clin Pract 2007;78(1):65-71.

[25] Myatt L. Placental adaptive responses and fetal programming. J Physiol 2006;572(Pt 1):25-30. 
[26] Teasdale F. Histomorphometry of the placenta of the diabetic women: class a diabetes mellitus. Placenta 1981;2(3):241-51.

[27] Tewari V, Tewari A, Bhardwaj N. Histological and histochemical changes in placenta of diabetic pregnant females and its comparision with normal placenta. Asian Pac J Trop Dis 2011;1(1):1-4.

[28] Elshennawy ATM. Effect of gestational diabetes on gross morphology, histology and histochemistry of human placenta. Endocrinol Metab Syndr 2016;5(1):227. 